\title{
Near-infrared fluorescence in robotic thyroidectomy
}

\author{
Liudmila Muraveika ${ }^{1}$, Emin Kose ${ }^{2}$, Eren Berber ${ }^{2,3}$ \\ ${ }^{1}$ Department of General Surgery, Robert Wood Johnson Medical School, New Brunswick, NJ, USA; ${ }^{2}$ Department of Endocrine Surgery, \\ ${ }^{3}$ Department of General Surgery, Cleveland Clinic, Cleveland, OH, USA \\ Contributions: (I) Conception and design: All authors; (II) Administrative support: None; (III) Provision of study materials or patients: None; (IV) \\ Collection and assembly of data: None; (V) Data analysis and interpretation: None; (VI) Manuscript writing: All authors; (VII) Final approval of \\ manuscript: All authors. \\ Correspondence to: Eren Berber, MD. Department of Endocrine Surgery and General Surgery, Cleveland Clinic, 9500 Euclid Ave/F20, Cleveland, OH \\ 44195, USA. Email: berbere@ccf.org.
}

\begin{abstract}
New imaging techniques using near-infrared (NIR) fluorescence in combination with remote access thyroidectomy have been studied in endocrine surgery to determine their utility, with the goal of reducing potential complications. Indocyanine green (ICG) imaging is a safe adjunct to remote access thyroid surgery. Nevertheless, experience with ICG is limited, and the caveats surrounding the use of ICG imaging in conventional thyroid surgery exist in remote access surgery as well. This report describes the various remote access techniques and considers the advantages and potential disadvantages of ICG in remote access thyroidectomy.
\end{abstract}

Keywords: Near-infrared (NIR); robotic thyroidectomy; endoscopic thyroidectomy; endocrine surgical procedures

Submitted Oct 17, 2019. Accepted for publication Dec 06, 2019.

doi: 10.21037 /gs.2019.12.15

View this article at: http://dx.doi.org/10.21037/gs.2019.12.15

\section{Introduction}

Remote access thyroidectomy allows patients undergoing thyroidectomy to avoid receiving neck incisions. The technique is a challenging task for a surgeon, as a surgeon's visual and tactile feedback allows him or her to identify correct planes and structures much more easily during an open operation (1). Following a total thyroidectomy, 0.9-6.6\% of patients experience permanent hypoparathyroidism (2). A missed removal of the abnormal parathyroid gland during the index thyroidectomy can result in multiple reoperations on an already scarred neck, which is associated with an increased rate of complications such as nerve injury and hypoparathyroidism (3). Novel imaging methods using near-infrared (NIR) fluorescence in combination with remote access thyroidectomy were recently compared to the conventional way of practice to define their use and their indications with the goal of reducing potential complications.

\section{Remote access techniques}

The goal of remote-access thyroid surgery is to remove the thyroid gland without making an incision in the neck. As Berber et al. (4) reported, the technique requires longer operative times, a steeper learning curve, and higher costs than conventional thyroidectomy. Nevertheless, this technique can be used on patients who have an indication for thyroid lobectomy and prefer, for cosmetic reasons, to avoid the typical incision (4). There are six major approaches to the technique of the remote access surgery: (I) endoscopic breast; (II) bilateral axillo-breast; (III) axillary; (IV) facelift; and (V) transoral.

Ohgami et al. (5) in 2000 described the first approach to remote-access thyroid surgery through the breast. This approach is performed by two $12-15 \mathrm{~mm}$ incisions in the area around both areolae. After injection of diluted adrenalin solution under the skin, subcutaneous and subplatysmal dissections are performed. Three centimeters 


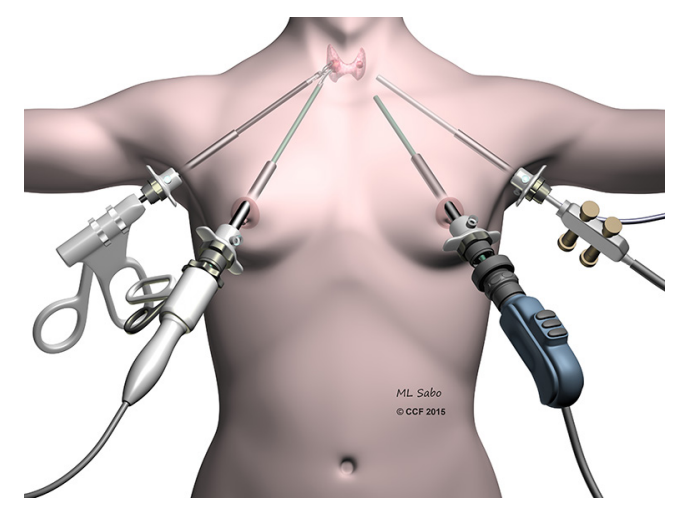

Figure 1 Illustration showing the bilateral axillary breast approach.

below the clavicular bone on the operative side, a $5-\mathrm{mm}$ port is inserted. The area is insufflated with carbon dioxide to a pressure of 5-6 $\mathrm{mmHg}$, and dissection with the aid of such insufflation provides access to the central neck. The thyroidectomy is then performed by means of an energy device. The approach is original and pioneering, yet it requires nuanced dissection, and carries the risk that the carbon dioxide used in insufflation may diffuse into remote tissue planes and cause serious complications.

In 2007 the bilateral axillo-breast approach (BABA) (Figure 1) was described by Choe et al. (6). The BABA originated as a variation on Shimazu et al.'s bilateral breast approach (7). In this approach 8-12-mm trocars are inserted in the areas of both areolae and axillae (Figure 1). The subcutaneous dissection is gained, as in the endoscopic breast approach, by insufflating $\mathrm{CO}_{2}(5-6 \mathrm{mmHg})$. For BABA thyroidectomy, endoscopic instruments and a vessel sealer are used, and dissection is performed as described in the conventional open thyroidectomy. Lee $e t$ al. adapted a robotic variation of BABA in 2009 (8) in order to control for a steep learning curve and reduce the need for significant endoscopic surgical skills. The endoscopic camera and vessel sealer are placed from the left and right breast ports, respectively. The robotic grasper and dissector are inserted in the axillary ports. This technique offers central access to the thyroid gland akin to that available in conventional thyroid surgery. However, as with the endoscopic breast approach, the extent of dissection and the risks of $\mathrm{CO}_{2}$ insufflation are important considerations.

The original axillary approach (Figure 2) described by Ikeda et al. begins with a $30-\mathrm{mm}$ axillar incision, through which 12 - and 5-mm trocars are inserted (9). After insufflation with carbon dioxide to a pressure of $4 \mathrm{mmHg}$,

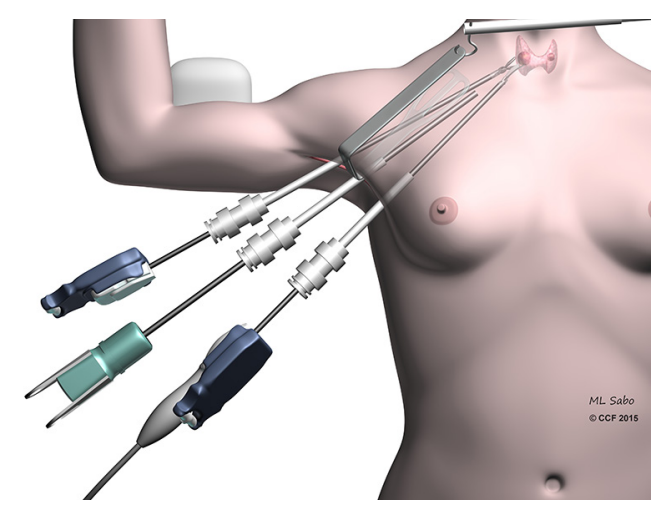

Figure 2 Illustration showing the setup and instrumentation for a transaxillary thyroidectomy.

a second $5-\mathrm{mm}$ trocar is inserted into the axilla. As in the open approach, access to the central neck is gained by separating the sternocleidomastoid muscle (SCM) from the sternohyoid muscle. Thyroidectomy is performed using an endoscopic vessel sealer and a grasper.

The gasless version of the axillary approach was developed by Yoon et al. (10) in 2006. Initially a 5-6-cm incision in the axilla is made, and a subcutaneous flap is extended to the collar bone. The central neck is entered between the sternal and clavicular heads of the SCM, and a static elevating retractor is placed. The thyroid is exposed by separating the strap muscles, and a robotic platform is introduced (Figure 2). A robotic 30-degree down camera, vessel sealer, and a grasper are introduced through this incision. In Yoon's et al. original description a second parasternal incision was involved, through which a fourth trocar would be inserted. The additional incision was subsequently abandoned. An important consideration in this technique is the expertise required to remove the contralateral lobe, to which access is limited.

In order to avoid an injury to the brachial plexus due to the overextension of the upper extremity, some have modified the approach by adopting a positioning of the ipsilateral arm closer to the torso, minimizing the overextension of the arm. This positioning benefits from direct access to the abnormal thyroid lobe, a lack of necessity for $\mathrm{CO}_{2}$ insufflation, and potential exposure of the contralateral thyroid lobe. However, significant training is required in order to properly create the axillary flap, and it is challenging to dissect the opposite thyroid lobe from a single incision (4).

Due to the difficulty of removing the contralateral lobe in the axillary approach, some have advocated for a bilateral 


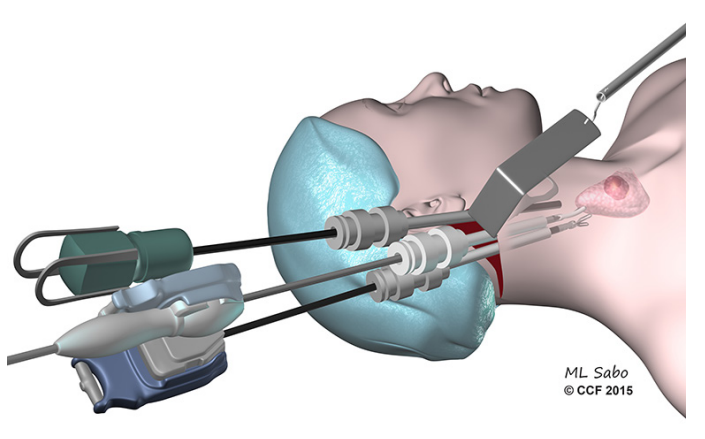

Figure 3 Illustration demonstrating the technique for the facelift approach for thyroidectomy.

axillary approach in cases where the entire thyroid must be removed. Others have argued that the use of a 30-degree scope and rotation of the operative bed toward the endoscope allows the contralateral side of the thyroid ample exposure.

The facelift approach (in both endoscopic and robotic forms) was described by Terris et al. (11) (Figure 3). An incision is made directly behind the ear, and extends back to the hairline such that it will be obscured by the ear. A subcutaneous flap is raised above the ipsilateral SCM. The omohyoid muscle needs to be exposed by retraction of the ipsilateral SCM and then retracted ventrally to visualize the strap muscles. Two retractors are employed to retract the subcutaneous flap and the SCM, respectfully. A 30-degree scope, vessel sealer, and a Maryland grasper are used for the dissection. Initially the superior thyroid pole is divided, then attention is turned to the recurrent laryngeal nerve (RLN) and parathyroids. Although this technique offers limited access to the contralateral lobe, it also allows a comparatively short flap distance and avoids the use of $\mathrm{CO}_{2}$ insufflation.

The transoral approach, which was pioneered by Dr. Angkoon Anuwong in Thailand and elaborated in a robotic context by Dr. Hoon Yub Kim in South Korea (Figure 4), involves trocars placed through the mouth. Experience with this approach is limited, and although the approach enables the removal of the thyroid without a skin incision, there is limited space for the removal of large nodules, and there are potential neurologic consequences.

Remote access thyroidectomies may be performed safely in high-volume centers, although the safety of the procedure has not been proven to be equivalent to the safety of a conventional thyroidectomy. The following

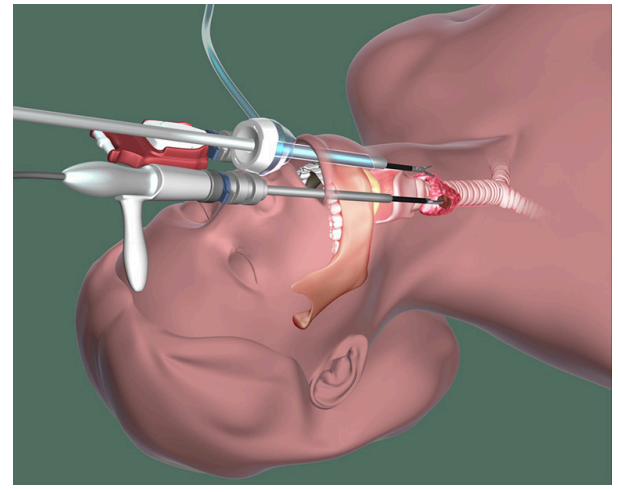

Figure 4 Illustration demonstrating the technique for the transoral approach for thyroidectomy.

recommendations are offered. The circumstances under which remote access surgery is offered should be limited, and strict selection criteria should be applied to potential patients. The practice of remote access procedures should be limited to surgeons performing a high volume of thyroid surgery. And the outcomes of remote-access thyroid surgeries should be monitored closely, so that the optimal approaches may be further refined (4).

\section{Utilization of the indocyanine green (ICG) in remote access thyroidectomy}

Kodak laboratories developed ICG $\left(\mathrm{C}_{43} \mathrm{H}_{47} \mathrm{~N}_{2} \mathrm{~N}_{2} \mathrm{O}_{6} \mathrm{~S}_{2}\right)$ initially for uses in photography. FDA later approved ICG for clinical use. It is an amphiphilic tricarbocyanine dye with a molecular mass of $776 \mathrm{Da}$ (12). ICG is administered intravenously and avidly binds to plasma proteins. It mainly stays in the intravascular space until it gets excreted by the liver. Parenchymal cells excrete the ICG in the bile approximately $8 \mathrm{~min}$ after injection (13). The dye reveals fluorescent changes when it is looked through a NIFI light spectrum at approximately $800 \times 820 \mathrm{~nm}$ (14) by using specially designed cameras projecting to a monitor. ICG has variable distribution in different tissues and can be favorably used for detection of hypervascularized tissues such as endocrine glands.

Zaidi et al. (15) initially studied the indications of ICG use in thyroidectomies and parathyroidectomies. Twentyseven patients underwent total thyroidectomy with ICG imaging for multinodular goiter $(n=13)$, thyroid cancer $(n=10)$, and Graves' disease $(n=4)$. Eighty-five parathyroid glands were identified visually, 71 (84\%) of which revealed ICG fluorescence. False negative rate was $6 \%$. 


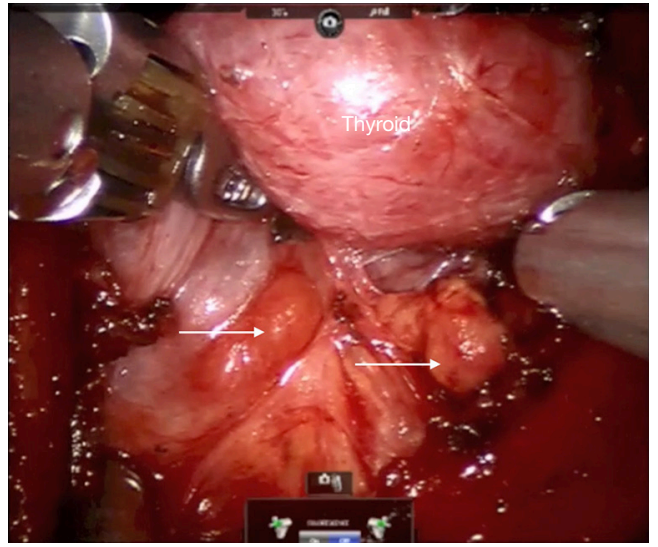

Figure 5 Illustrates thyroid with arrows pointing to the location of the parathyroid glands.

Postoperatively, 3 patients (11\%) had a serum calcium value less than $8 \mathrm{mg} / \mathrm{dL}$. ICG uptake after total thyroidectomy correlated with postoperative parathyroid hormone (PTH) levels: mean on postoperative day (POD) \#1 PTH of those patients with at least two parathyroid glands exhibiting $<30 \%$ fluorescence was $9 \mathrm{pg} / \mathrm{mL}$; whereas those with fewer than two demonstrating $<30 \%$ fluorescence had a POD \#1 $\mathrm{PTH}$ of $19.5 \mathrm{pg} / \mathrm{mL}(\mathrm{P}=0.05)$. Zaidi et al. (15) ICG imaging of parathyroid glands during total thyroidectomy was feasible and could be a useful adjunct in identifying those patients at risk for postthyroidectomy hypoparathyroidism.

The primary utility of ICG fluorescence in thyroid surgery is to help delineate parathyroids and their blood supply (Figures 5,6). In remote access thyroidectomy it remains to investigate whether NIR light-induced ICG fluorescence can be used in the identification (and thereby the preservation) of parathyroid glands. Yu et al. (16) used ICG and Firefly technology to identify the parathyroid glands during BABA robotic thyroidectomy. This was a case-control study with a prospectively recruited consecutive series and a retrospectively selected control group to evaluate the usefulness of ICG. The ICG group revealed much lower percentage of incidental parathyroidectomy than the control group ( $0 \%$ vs. $15.9 \%, \mathrm{P}=0.048)$. The study concluded that ICG with NIR light may feasibly identify and preserve the parathyroid glands during the total thyroidectomy (16).

Given its extensive use, ICG has been determined to have a relatively safe drug profile. However, adverse reactions and a few deaths have been reported in the literature (17). Hope-Ross et al. (17) used intravenous ICG

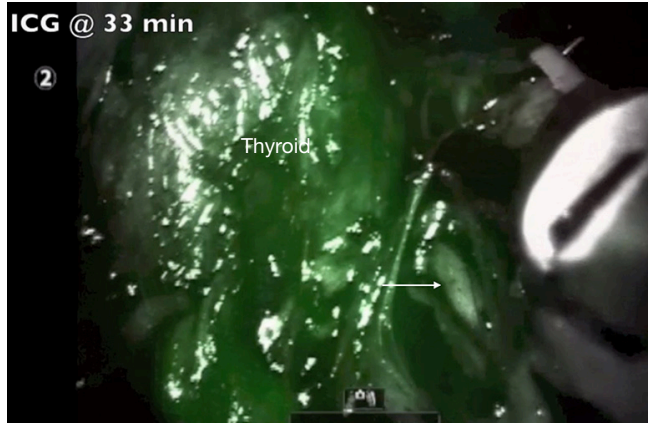

Figure 6 Illustrates the thyroid gland with arrow pointing to the inferior RLN after ICG administration. RLN, recurrent laryngeal nerve; ICG, indocyanine green.

for video angiography in 1,226 patients and reported an incidence of mild, moderate, and severe complications to be $0.15 \%, 0.2 \%$, and $0.05 \%$ respectively. ICG solution has sodium iodide which along with the molecule itself been implicated in these reactions, and therefore, ICG should be avoided in patients with an iodine allergy. The typical dose for standard clinical use $(0.1-0.5 \mathrm{mg} / \mathrm{mL} / \mathrm{kg})$ is well below the toxicity level.

Twenty-five mg of ICG usually gets diluted in $10 \mathrm{cc}$ of sterile saline. The toxic level for ICG is $5 \mathrm{mg} / \mathrm{kg}$, so the titrated administration of $5-10 \mathrm{mg}$ of ICG in multiple timed doses during the operation has tested itself to be safe. During thyroidectomy, ICG helps to localize parathyroid glands and assess their vascular supply and possible avascularization of the gland. Usually once the central neck is carefully dissected, thyroid visualized and ipsilateral thyroid lobe is retracted towards the trachea, the anesthesiologist administers $5 \mathrm{mg}$ of ICG in $2.5 \mathrm{mg} / \mathrm{mL}$ solution through an intravenous access. A Firefly camera (Figure 7) is used to observe the ICG uptake in the parathyroid and thyroid glands approximately 30-60 s later. The same procedure applies to the opposite side. The vascular uptake and appearance of the parathyroid glands depends on how proximal these grands are to the thyroid itself. ICG could be administered as well after lobectomy to reevaluate presence and perfusion of parathyroids. Another utility is to help with the identification of the RLN due to the contrast gradient created with the surrounding soft tissues. Although the concept is attractive in providing another tool to the surgeon to detect parathyroid glands, a frustration has been the interference of fluorescence in the field by the thyroid, which limited the ability to distinguish parathyroid glands. A second utility is to assess the 


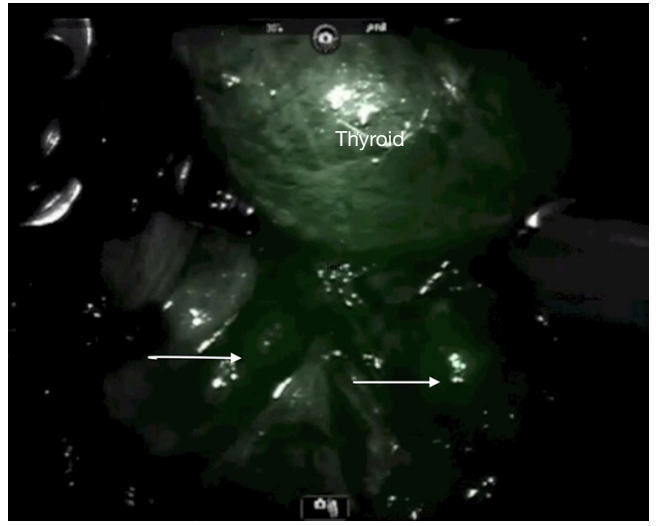

Figure 7 Illustrates the thyroid gland with arrows pointing to the inferior parathyroids after ICG administration. ICG, indocyanine green.

perfusion of parathyroid glands at the end of thyroidectomy to ensure viability. In our experience, the challenge has been false positivity and false negativity of this modality.

\section{Conclusions}

ICG imaging is a safe adjunct to remote access thyroid surgery. Nevertheless, experience with ICG is limited. The challenges around the utility of ICG imaging in conventional thyroid surgery exist in the remote access surgery as well.

As Rudin et al. (1) demonstrated, during thyroidectomy $84 \%$ of parathyroid glands revealed ICG fluorescence. Thus, the parathyroid glands could be noticed before carrying on the dissection of the thyroid. Knowing the location of the parathyroid glands would let the surgeon minimize injury to those glands' blood supply (1). However, the thyroid gland also demonstrates an intense fluorescence with ICG administration, which may prevent the identification of the parathyroid glands. There is no difference in uptake of the ICG dye between the parathyroid and the thyroid glands. As per recent studies, ICG dye could be used in evaluation of the blood supply of parathyroid glands at the end of total thyroidectomy (1). In $6 \%$ of the cases studied, ICG dye revealed false negative results, where the natural color of the parathyroid gland was appreciated without the ICG injection and was not appreciated any more after injection of the ICG dye.

We believe that the use of the ICG fluorescence may be advantageous, but brings minimal input to the procedure results and is not necessary for detection of the parathyroid glands. It is certainly possible to administer the ICG before making an incision, but unfortunately it will not help to minimize the thyroid uptake of the dye. We have not observed a significant contrast distinction between parathyroid and thyroid glands. It is to be investigated in the future if there is a parathyroid protein which will be able to bind to the ICG and become specific to the parathyroid tissue (1).

\section{Acknowledgments}

None.

\section{Footnote}

Conflicts of Interest: The authors have no conflicts of interest to declare.

Ethical Statement: The authors are accountable for all aspects of the work in ensuring that questions related to the accuracy or integrity of any part of the work are appropriately investigated and resolved.

\section{References}

1. Rudin AV, Berber E. Impact of fluorescence and autofluorescence on surgical strategy in benign and malignant neck endocrine diseases. Best Pract Res Clin Endocrinol Metab 2019;33:101311.

2. Bilezikian JP, Khan A, Potts JT Jr, et al.

Hypoparathyroidism in the adult: epidemiology, diagnosis, pathophysiology, target-organ involvement, treatment, and challenges for future research. J Bone Miner Res 2011;26:2317-37.

3. Rudin AV, Thompson G. Revision parathyroidectomy. In: Parameswaran R, Agarwal A. Evidence-based endocrine surgery. Singapore: Springer Singapore, 2018:293-305.

4. Berber E, Bernet V, Fahey TJ 3rd, et al. American thyroid association statement on remote-access thyroid surgery. Thyroid 2016;26:331-7.

5. Ohgami M, Ishii S, Arisawa $Y$, et al. Scarless endoscopic thyroidectomy: breast approach for better cosmesis. Surg Laparosc Endosc Percutan Tech 2000;10:1-4.

6. Choe JH, Kim SW, Chung KW, et al. Endoscopic thyroidectomy using a new bilateral axillo-breast approach. World J Surg 2007;31:601-6.

7. Shimazu K, Shiba E, Tamaki Y, et al. Endoscopic thyroid surgery through the axillo-bilateral-breast approach. Surg 
Laparosc Endosc Percutan Tech 2003;13:196-201.

8. Lee KE, Rao J, Youn YK. Endoscopic thyroidectomy with the da Vinci robot system using the bilateral axillary breast approach (BABA) technique: our initial experience. Surg Laparosc Endosc Percutan Tech 2009;19:e71-5.

9. Ikeda Y, Takami H, Sasaki Y, et al. Endoscopic resection of thyroid tumors by the axillary approach. J Cardiovasc Surg (Torino) 2000;41:791-2.

10. Yoon JH, Park CH, Chung WY. Gasless endoscopic thyroidectomy via an axillary approach: experience of 30 cases. Surg Laparosc Endosc Percutan Tech 2006;16:226-31.

11. Terris DJ, Singer MC, Seybt MW. Robotic facelift thyroidectomy: patient selection and technical considerations. Surg Laparosc Endosc Percutan Tech 2011;21:237-42.

12. Alander JT, Kaartinen I, Laakso A, et al. A review of indocyanine green fluorescent imaging in surgery. Int J

Cite this article as: Muraveika L, Kose E, Berber E. Nearinfrared fluorescence in robotic thyroidectomy. Gland Surg 2020;9(Suppl 2):S147-S152. doi: 10.21037/gs.2019.12.15
Biomed Imaging 2012;2012:940585.

13. Boni L, David G, Mangano A, et al. Clinical applications of indocyanine green (ICG) enhanced fluorescence in laparoscopic surgery. Surg Endosc 2015;29:2046-55.

14. Luo S, Zhang E, Su Y, et al. A review of NIR dyes in cancer targeting and imaging. Biomaterials 2011;32:7127-38.

15. Zaidi N, Bucak E, Yazici P, et al. The feasibility of indocyanine green fluorescence imaging for identifying and assessing the perfusion of parathyroid glands during total thyroidectomy. J Surg Oncol 2016;113:775-8.

16. Yu HW, Chung JW, Yi JW, et al. Intraoperative localization of the parathyroid glands with indocyanine green and Firefly $(\mathrm{R})$ technology during BABA robotic thyroidectomy. Surg Endosc 2017;31:3020-7.

17. Hope-Ross M, Yannuzzi LA, Gragoudas ES, et al. Adverse reactions due to indocyanine green. Ophthalmology 1994;101:529-33. 